\title{
Intestinal Parasites And Associated Factors Among Food Handlers In Mizan-Aman Town, Bench Maji Zone, Southwest Ethiopia
}

\author{
Wasihun Adraro \\ Mizan Aman Health Science College \\ Girma Mamo \\ Mizan Aman Health Science College \\ Aklilu Mamo \\ Wachamo University \\ Mesenbet Muluken \\ Mizan Aman Health Science College \\ Samuel Sahile \\ Mizan Tepi University \\ Esrael Derkiyab \\ Mizan Aman Health Science College \\ Tigistu Toru ( $\square$ tigistutoru112@gmail.com ) \\ Wolkite University
}

\section{Research article}

Keywords: Intestinal parasites, Food handlers, Food and drink establishment

Posted Date: February 3rd, 2020

DOl: https://doi.org/10.21203/rs.2.22433/v1

License: (c) (1) This work is licensed under a Creative Commons Attribution 4.0 International License. Read Full License 


\section{Abstract}

Background: - Food borne diseases are a challenge for both developed and developing countries and are a leading cause of illnesses and deaths in developing countries. Regardless of concentrative hard work for several years, food borne diseases has remained a major global public health issue with substantial morbidity and mortality associated with the consumption of contaminated food staffs. Parasitic infection is among the major disease especially in developing countries and sub-Saharan countries including Ethiopia.

Objective: -This study was aimed to determine the prevalence of intestinal parasites and associated factors among food handlers working in food and drink establishments at Mizan Aman town southwest Ethiopia.

Method:- A community based cross sectional study design was employed. Four hundred eighteen study participants were randomly selected from a total of 209 foods and drinks establishment in Mizan Aman Town, Bench Maji Zone, and Southwest Ethiopia. Epidata version 3.1 used for data entry while SPSS version 21 used for analysis. Descriptive and logistic regression analysis carried out ; predictor variables at $95 \% \mathrm{Cl}$ using $\mathrm{p}-$ value $\leq 0.05$ were declared as statistically significant.

Result: Among 399 participants, 203(50.9\%) were female and 194(49.1\%) were male. Almost half 194 (48.6 \%) of the participants age was below 20 years. The overall prevalence of intestinal parasites among the study subjects was $26.1 \%$; from this Ascaris lumbricoides $7.3 \%$ and Teniasis species $5 \%$ were the predominant parasites identified from the stool of study participants.

Conclusion: The study identified high prevalence of intestinal parasites among study participants who worked for less than one year duration, wear hand jewelry, not practice hand washing routinely, not wearing hair net, food preparation during sickness and use the same equipment for raw and cooked food serving. Training about safe food handling and other hygienic practices should be encouraged for better personal and community health status. On the other hand, all concerned should pay attention to safe guard consumers' health. Key terms: Intestinal parasites, Food handlers, Food and drink establishment

\section{Background}

Food borne diseases are a challenge for both developed and developing countries and are a leading cause of illnesses and deaths in developing countries (1). Regardless of concentrative hard work for several years, food borne diseases remain a major global public health issue with substantial morbidity and mortality associated with the consumption of contaminated food staffs ((1),(2)).

Correspondingly, according to WHO, food handling personnel play significant role in ensuring food safety throughout the chain of food production. Therefore, to reduce food borne illnesses, it is crucial to gain an understanding of the knowledge and practices of food handlers. However, several factors contribute to the spread of food borne outbreaks by food service workers (3).Parasite is an organism that is entirely dependent on another organism, referred to as its host, for all or part of its life cycle and metabolic requirements(4).

Parasitic infection is among the major disease in the world especially developing countries and sub-Saharan countries (5). According to World Health Organization (WHO) estimation the 3.5 billion people worldwide are infected with intestinal parasites and nearly greater than 450 million of them are sick due to intestinal parasites, 
the majority are children (6). Many various studies have reported the presence of relatively high prevalence rates of the major protozoan and helminthes infections in tropical countries, where parasitic diseases remain among the heaviest and serious health problems (7), (8).

The cause for high distribution of parasites in some parts of the country are a result of specific climate of the regions, local customs, age, job, educational level of people, attitude of peoples on parasitic infection and the use of human and animal fertilizers in agriculture and floriculture(9). Due to geographical location, climate, extent of the area, and cultural and biological characteristics, there is a suitable environment for the activity of various parasites in Ethiopia (10).The absence of clean and safe water, high population density, lack of proper disposal of waste, noncompliance with health standards, lack of adequate washing of vegetables, lack of washing hands before and after toilet and feeding of uncooked meat and drinking un boiled(non- pasteurized) milk lead to high prevalence of intestinal parasites(11). Similarly, where poor environmental sanitation, poor personal hygiene and low level of education are prominent(12). As studies report in different parts Ethiopia there is different types of parasites and different level of infection which are studied different parts of a country (5), (13).Ethiopian ministry of health is prioritize the parasitic disease by preparing national master plan for neglected tropical disease (NTDS) control strategies (14). The high incidence of parasites has been indicated as they are transmitted by food borne and feaco-orally and their negative impact on community was explained. Some of negative consequences are malnutrition, stunt growth, anemia and cognitive impairment (17). Food-handlers who are working different hotels and cafeteria harbor and excrete intestinal parasites may contaminate food and serve as continues source of food-borne infection (10). The investigation of parasitic infections forms a major activity in diagnosing and performing different publications

To prevent, food borne illnesses, all food handlers are required to practice food hygiene and safety activities. Food hygiene is the set of basic principles employed in the systematic control of the environmental conditions during production, packaging, delivery/transportation, storage, processing, and preparation, selling and serving of food in such a manner as to ensure that food is safe to consume. However, improper and inconsistent food hygiene and safety activities can pose a health threat in developing countries due to difficulties in securing optimal hygienic food handling practices (15), (16).

\section{Methods}

\section{Study area and design}

The study was conducted at Mizan Aman town , Bench Maji zone in SNNP Regional State which is located in Southwest Ethiopia $561 \mathrm{~km}$ far from Addis Ababa, with a total population of 57,537, of those 30,379 were males and 27, 158 were females (17). There are 135 and 189 food and drink establishments within Aman and Mizan administration town respectively. Totally 324 food and drink establishments had been registered by Mizan Aman town Trade and Industry Office in 2009 E.C. The study was conducted from March 1/2010E.C- April $30 / 2010$ E.C. A community based cross-sectional study design was used.

\section{Sample size and sampling technique}

Sample size was calculated by using a single population proportion formula assuming 95\% confidence interval, $5 \%$ margin of error and prevalence of intestinal parasites $44.1 \%$ among food handlers' at Jimma zone, Yebu town was taken as proportion (12).Therefore, the final sample size were 418. 
Therefore, Where $P=0.44 \% \quad Z=95 \% \quad d=5 \%$ ) and $10 \%$ non-response rate.

$$
n=\frac{\left.(z a / 2)^{2}\right) * p(1-p)}{d^{2}}=418
$$

$=418$

\section{Data collection tools and methods}

A pretested structured questionnaire was adapted from other related researches in English then translated to Amharic for study purpose. Each parts of data collection items were properly coded for analysis methods. More over data completeness was checked on daily bases.

A cleaned, coded and tight-lid plastic container was used to collect stool from randomly selected food handlers. All participants were informed about the purpose of the study and after getting their willingness questions were provided in sequential manner. About a paean size of the stool samples were collected from each selected food handlers. Collected stool specimen was transported to Mizan Aman Health Science College laboratory within an hour. Parasitological assessment was performed by qualified laboratory technologists using both the physiological saline and iodine wet mount and formol ether concentration techniques as described on the standard. Dispensing the saline preferably from a small dropper bottle which can be closed when not in use to avoid contaminating the reagent was done (12). The direct saline wet mount was employed not to miss trophozoites of E. histolytica and G. lamblia. However, in this study, no trophozoites were recorded. All of the parasites detected by direct saline wet mount were also detected by Formol ether concentration technique. Thus, the results of Formol ether concentration technique were used for analyses. Finally, respondents who were infected with intestinal parasites linked to health facilities in accordance with keeping confidentiality.

\section{Statistical data analysis}

Data were entered, cleaned by using epi data version 3.1 and transported to SPSS version 21.0. For analysis purpose. Then, percentage and frequency distribution was performed. Bivariate analysis also used in describing the association between dependent and independent variables. Variables having a $p$-value of less than 0.25 in the bivariate analysis were considered for multivariate logistic regression. A $p$-value of $\leq 0.05$ were used to indicate statistical significance.

\section{Results}

Socio demographic characteristics

A total of 418 food handlers were selected but 19 of them refuse to participate so that the response rate was 95.4\%. Among 399 participants 203(50.9\%) were female and 194(49.1\%) were male. Regarding the age of participants, less than 20 years were the majority 194 (48.6\%) and 55(13.7\%) of them were infected by intestinal parasites which were the highest proportion from total prevalence of parasites. Only $27(6.8 \%)$ food handlers had training in food safety and about $48(12 \%)$ of them had medical check-up. 
From the total study subjects $(n=399), 19$ of them were not willing to participate for a stool examination. About $104(26.1 \%)$ of food handlers were infected with different species of intestinal parasites.

\section{Bivariate and multivariate analysis}

Bivariate analysis was conducted to identify candidate variables for multivariate analysis. All candidate variables from Bivariate result (<P-value 0.25) were entered into multivariate analysis. Accordingly job category, Age, educational status, Working experience, hand washing habit and food contact with bare hand were candidates variables for multivariate analysis. From multivariate analysis variables whose $p$-value $<0.05$ taken as significantly associated factors (Table 1 ).

The odd of infection is $48 \%$ less likely in the participants who served for more than 10 years compared to that of participants who served for less than 1 year.The risk of infection among the study participants who wash their hands after food preparation is 1.37 times more likely to be infected compared to respondents who wash their hands routinely. Respondents who did not trim their fingers nails were 1.89 times more likely to be infected than that of the respondents who trimmed their finger nails. The risk of infection in Study participants who does not use common knife to cut raw meat and other foods were $43 \%$ times lower than those who use common knife. 
Table 1

Bivariate and Multivariate analysis of intestinal parasites and associated factors among food handlers in Mizan Aman town, Bench Maji Zone, Southwest Ethiopian( $n=399) 2010$ E.C

\begin{tabular}{|c|c|c|c|c|c|}
\hline \multirow[t]{2}{*}{ Variables } & & \multicolumn{2}{|c|}{ Infection status } & \multirow[t]{2}{*}{ COR $(95 \% \mathrm{Cl})$} & \multirow[t]{2}{*}{ AOR $(95 \% \mathrm{Cl})$} \\
\hline & & $\begin{array}{l}\text { Yes } \\
\text { N (\%) }\end{array}$ & $\begin{array}{l}\text { No } \\
\mathrm{N}(\%)\end{array}$ & & \\
\hline \multirow[t]{5}{*}{ Age } & $17-19$ & $55(28.35)$ & $139(77.65)$ & 1 & 1 \\
\hline & $20-35$ & $38(22.4)$ & 132(77.6) & $1.74(.053,2.215)$ & $1.210(0.123,3.741)$ \\
\hline & $36-50$ & $4(36.6)$ & $7(63.4)$ & $.192(1.195,2.460)^{\star \star}$ & $2.67(0.723,3.12)$ \\
\hline & $51-65$ & $6(30)$ & $14(70)$ & $.923(.338,2.525)$ & $0.915(0.122,6.367)$ \\
\hline & $>65$ & $1(25)$ & $3(75)$ & $1.187(.121,11.659)$ & $4.21(0.983,2.111)$ \\
\hline \multirow{5}{*}{$\begin{array}{l}\text { Education } \\
\text { status of } \\
\text { the } \\
\text { respondent }\end{array}$} & University & $5(29.4)$ & 11(70.6) & $.667(.187,2.379)$ & $1.500(.420,5.325)$ \\
\hline & Collage & $12(41.1)$ & $17(58.9)$ & $0.429(.154,1.194)$ & $2.329(.837,6480$ \\
\hline & High school & $25(26.6)$ & $69(73.4)$ & $.678(0.836, .360)$ & \\
\hline & Primary school & $52(24)$ & $165(76)$ & $.021(.962, .444)^{\star \star}$ & $0.76(0.835,2.712)$ \\
\hline & $\begin{array}{l}\text { Cannot read and } \\
\text { write }\end{array}$ & $10(23.3)$ & $33(76.7)$ & 1 & 1 \\
\hline \multirow{4}{*}{$\begin{array}{l}\text { Working } \\
\text { experience }\end{array}$} & $<1 \mathrm{yr}$ & $56(28.4)$ & 141(71.6) & 1 & 1 \\
\hline & $1-5 y r$ & $42(24.4)$ & $131(75.6)$ & $1.45(0.23,0.897)^{\star \star}$ & 2.12(0.478.7.123) \\
\hline & 6-10yr & $5(19.2)$ & 21(70.8) & & \\
\hline & $>10 y r$ & $1(25)$ & $3(75)$ & $2.49(0.09,0.888)$ & $\begin{array}{l}\text { AOR } 0.52,95 \% \mathrm{Cl} \\
(2.430,5.012)^{\star \star}\end{array}$ \\
\hline \multirow{5}{*}{$\begin{array}{l}\text { When do } \\
\text { you wash } \\
\text { your } \\
\text { hands? }\end{array}$} & $\begin{array}{l}\text { Before food } \\
\text { preparation }\end{array}$ & $7(26.9)$ & 19(73.1) & $0.99(0.39,2.46)$ & $0.56(0.19,1.6)$ \\
\hline & $\begin{array}{l}\text { Before equipment } \\
\text { washing }\end{array}$ & $12(42.8)$ & $16(57.2)$ & $0.49(0.21,1.08)$ & $1.67(0.63,4.41)$ \\
\hline & After toilet visit & $13(27.1)$ & $35(76.9)$ & $0.98(0.49,1.97)$ & $0.82(0.36,1.88)$ \\
\hline & $\begin{array}{l}\text { After food } \\
\text { preparation }\end{array}$ & $9(14.7)$ & $52(85.3)$ & $2.1(0.98,4.52)$ & $1.37(0.15,0.9)^{\star \star}$ \\
\hline & Repeatedly/Routinely & $63(26.6)$ & 173(73.4) & 1 & 1 \\
\hline \multirow{2}{*}{$\begin{array}{l}\text { Does the } \\
\text { respondent } \\
\text { trim } \\
\text { his/her } \\
\text { finger? }\end{array}$} & Yes & $52(29.7)$ & $175(70.3)$ & 1 & 1 \\
\hline & No & $52(30.2)$ & $120(69.8)$ & $1.92(0.23,0.245)^{\star \star}$ & $1.89(1.01,3.960)^{\star \star}$ \\
\hline \multirow{2}{*}{$\begin{array}{l}\text { Do you use } \\
\text { common } \\
\text { knife for } \\
\text { cutting raw }\end{array}$} & Yes & $53(30.5)$ & $121(69.5)$ & 1 & 1 \\
\hline & No & $51(22.7)$ & 174(77.3) & 7.89(0.78,3.129) & $0.57(3.61,5.54)^{\star \star}$ \\
\hline
\end{tabular}




\section{Discussion}

Several studies across the world have determined the prevalence of intestinal parasites among food handlers. The prevalence rates of the intestinal parasites infections among food-handlers in different part of the world range from $28.7-52.2 \%$ (12). The results of this study revealed that intestinal parasites prevalence among the study participants was $26.1 \%$. This is comparable with the finding of $(25 \%)$ in Gonder University Ethiopia [6]. However it is higher than what was reported in northern Iran, the prevalence of intestinal parasites was $3.73 \%$ (4) and in Axum, Ethiopia reported that the overall prevalence rate of intestinal parasite was 14.5\%(5).

On the other hand, the result of this study was lower than a cross sectional study revealed in Bahir Dar town, 158 (41.1\%) of food handlers had intestinal parasites infection (7). Another similar study in Arbaminch University showed that $36 \%$ of the study participants found to be infected with intestinal parasites(8) and a study conducted in Jimma Zone, Yebu town reported highest rate of intestinal parasite $44.1 \%(9)$. The differences might be due to differences in climate, geographical location, socio-demographic features of the populations and sample size. The prevalence among food handlers probably reflects the prevalence in the general population. This is because of among 104 infected food handlers 95(23.80\%) were no special food handling training was given.

The predominant parasite identified from the stool specimens in this study was positive for Ascarisis lumbricoides 29(7.3\%), followed by Teniasis 20(5\%) and Entamoebahistolytica 14(3.5\%). This was inconsistent with the finding of a similar study conducted in Gondar University, Giardia lamblia was the most prevalent parasites 22(11\%), followed by Ascarisis lumbricoides 13(6.5\%) and Entamoeba histolytica 12(6\%)(6).

According to our research finding, the odd of infection is $48 \%$ less likely in the participants who served for more than 10 years compared to that of participants who served for less than 1 year. But, according to the research done in southern part of Ethiopia, there was no association between year of service and prevalence of parasitic infection (2). The risk of infection among the study participants who wash their hands only after food preparation is 1.37 times more likely to be infected when compared to respondents who wash their hands routinely. The habit of hand washing practice was similarly associated with infection rate according to research conducted in Arbamich (2). Respondents who did not trim their fingers were 1.89 times more likely to be infected than that of the respondents who trimmed their fingers. This finding was similar with that of Arbaminch according to the report; parasitic infection rate was 2 times higher among the participants who didn't trim their finger nails.

\section{Conclusion}

The study also revealed that majority of the food handlers did not wear gown, hair net, and did not have medical checkup either before or after assigning as food handlers. Therefore, much has to be done to improve the personal hygiene of the food handlers. Pre-placement and periodic screening of food handlers for parasites and practicing hygienic practices 


\section{Recommendation}

Based on this study findings, training will be given to voluntary food handlers and owners of food and drink establishments in Collaboration with Mizan Aman town Trade and Industry office and culture and Tourism office.

\section{Limitation Of The Study}

The main limitation of this study was not able to include all intestinal parasites because of lack of specific reagent for specific parasites identification.

\section{Abbreviations}

SPSS: Statistical Package for Social Science

WHO: World Health Organization

SNNPR: Southern nations and nationalities, and peoples region

AOR: Adjusted odds ratio

\section{Declarations}

\section{Ethics approval and consent to participate}

The research was approved by Research Ethics Committee (REC) of Institute of Mizan Aman collage of health science. REC has written ethical clearance letter by mentioning entitled study which followed all ethical issues as respected and guaranteed. Informed Verbal consent for participation was obtained from each participant before running the interview because we used interview administered questionnaire along with stool sample collection. Stool sampling was collected after delivering adequate information about the objective of the study, participants rights for whether to participate or not was similarly ensured. Confidentiality was kept by avoiding their name and other personal identifications from the questionnaire format. Privacy was kept while interviewing each respondent.

\section{Consent for publication}

This part is not applicable because the manuscript contains no any individual person's data in any form (including individual details, images or videos).

\section{Availability of data and materials}

All data and materials in this manuscript are available from the corresponding author on reasonable request.

\section{Competing interest}

Authors declare that they have no competing interests.

\section{Funding}


The study was conducted by fund released from Mizan Aman Collage of Health Science, the college has annual budget to support researchers rather than no role in preparing research design, data collection, analysis and manuscript writing. Those roles are posed to equally authors.

\section{Authors' contribution}

TT: revised and commented on design, analysis, manuscript, WA: originated research concept, design, participate analysis and preparing manuscript, GM : originated research concept, design, supervised data quality, participated analysis and preparing manuscript, AM : participated in design, participated analysis and preparing manuscript: , MM: participated in design, participated analysis and preparing manuscript, SS: participated in design and conducted analysis and, ID: participated in design, participated analysis and preparing manuscript.

\section{Acknowledgement}

We would like to extend our grateful thanks to Mizan Aman collage of health science for funding the study. We would like to thank Mizan Aman town administration for their permission to getting access to food handlers and their personal information. Lastly; we are indebted and appreciate those participants for all their tolerance and cooperation without being limited with so many challenges they were in.

\section{Authors' details}

TT: Lecturer at Wolkite University, Department of nursing ,WA: Lecturer at Mizan Aman Health Science College, Department of nursing ,GM: Lecturer at Mizan Aman Health Science College, Department of public health, AM: Lecturer at Wachamo University , Department of nursing, MM: Instructor at Mizan Aman College of Health Science, Department of public health, SS: Instructor at Mizan Tepi University, Department of Medical Laboratory, ED: Lecturer at Mizan Aman College of Health Science, Department of public health.

\section{References}

1.Baluka Sa, Miller R, Kaneene Jb. Hygiene practices and food contamination in managed food service facilities in Uganda. African Journal of food science. 2015;9(1):31-42.

2.Mama M, Alemu G. Prevalence and factors associated with intestinal parasitic infections among food handlers of Southern Ethiopia: cross sectional study. BMC public health. 2015;16(1):105.

3.Mekasha T, Neela S, Kumela D. Food safety knowledge, practice and attitude of food handlers in traditional hotels of Jimma Town, Southern Ethiopia. Annals Food Science and Technology. 2016;17(2):507-17.

4.Williams J. District laboratory practice in tropical countries. Part 1: Monica Cheesbrough. Doddington, Cambridgeshire: Tropical Health Technology, 1998. viii+ 456pp. Price£ 10.90 (surface post) orf 19.00 (airmail). ISBN 9507434-4-5 [Also available from Cambridge University Press (£ 35.00; ISBN 0-521-66547-7)]. No longer published by Elsevier; 2000. 
5.Malakotian M, Hosseini M, Bahrami H. Survey of the parasires of vegetable in Kerman province. Medical Journal of Hormozgan University. 2009;13(1):55-62.

6.Kulkumthorn M, Nuchprayoon S. The prevalence of intestinal parasitic infections among school children in the central region of Thailand. J Med Assoc Thai. 2006;89(11):1928-33.

7.Pandey S, Lo AL, Shrestha RB. Intestinal parasitic infections among school children of Northern Kathmandu, Nepal. Asian Pacific Journal of Tropical Disease. 2015;5:S89-S92.

8.Alum A, Rubino JR, ljaz MK. The global war against intestinal parasites-should we use a holistic approach? International Journal of Infectious Diseases. 2010;14(9):e732-e8.

9.Ridley JW. Parasitology for medical and clinical laboratory professionals: Cengage Learning; 2012.

10.Assefa T, Tasew H, Wondafrash B, Beker J. Contamination of bacteria and associated factors among food handlers working in the student cafeterias of Jimma University Main Campus, Jimma, South West Ethiopia. Alternative \& Integrative Medicine. 2015.

11.Soleimnanpoor $\mathrm{H}$, Zohor A, Ebrahimzadeh A. The survey of parasitic contamination of vegetables in Zabol city during 2011-2012. Zabol University of Medical Sciences. 2013;3(2):40-7.

12. Tefera T, Mebrie G. Prevalence and predictors of intestinal parasites among food handlers in Yebu town, southwest Ethiopia. PLoS One. 2014;9(10):e110621.

13.Wegayehu T, Tsalla T, Seifu B, Teklu T. Prevalence of intestinal parasitic infections among highland and lowland dwellers in Gamo area, South Ethiopia. BMC public health. 2013;13(1):151.

14.Deribe K, Meribo K, Gebre T, Hailu A, Ali A, Aseffa A, et al. The burden of neglected tropical diseases in Ethiopia, and opportunities for integrated control and elimination. Parasites \& vectors. 2012;5(1):240.

15.Ifeadike CO, Ironkwe OC, Adogu PO, Nnebue CC. Assessment of the food hygiene practices of food handlers in the Federal Capital Territory of Nigeria. Tropical journal of medical research. 2014;17(1):10.

16.Kumie A, Mezene A, Amsalu A, Tizazu A, Bikila B. The sanitary condition of food and drink establisment in Awash-Sebat Kilo town, Afar region, Ethiopia. Ethiopian Journal of Health Development. 2006;20(3).

17.CSA, Ethiopia, 2007. 